
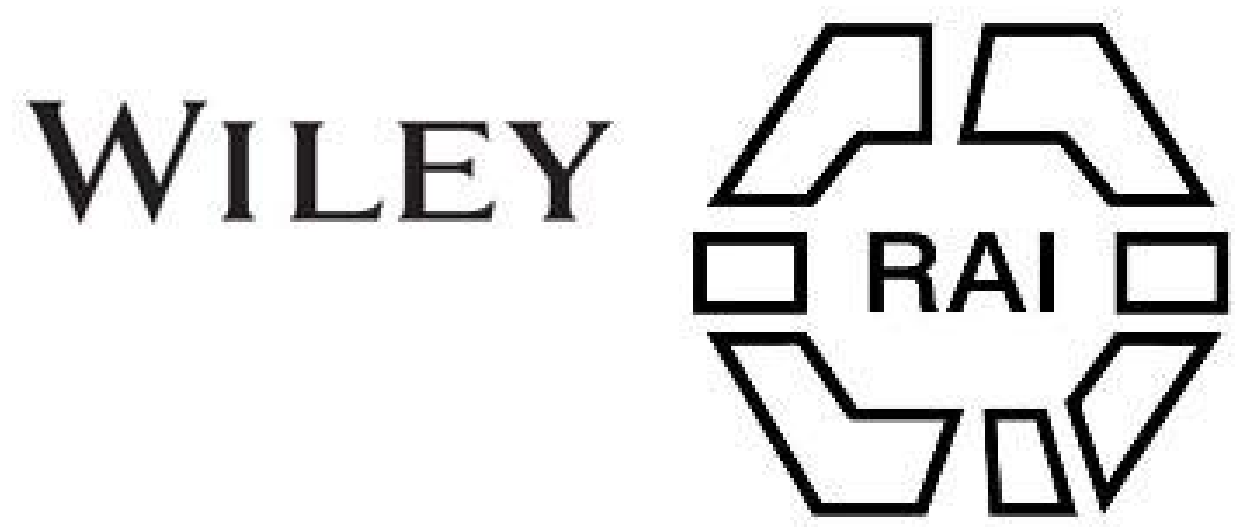

\title{
22. Peruvian Tapestries at Toronto.
}

\section{Author(s): A. C. Breton}

Source: Man, Vol. 18 (Mar., 1918), pp. 33-36

Published by: Royal Anthropological Institute of Great Britain and Ireland

Stable URL: http://www.jstor.org/stable/2788421

Accessed: 26-06-2016 11:26 UTC

Your use of the JSTOR archive indicates your acceptance of the Terms \& Conditions of Use, available at

http://about.jstor.org/terms

JSTOR is a not-for-profit service that helps scholars, researchers, and students discover, use, and build upon a wide range of content in a trusted digital archive. We use information technology and tools to increase productivity and facilitate new forms of scholarship. For more information about JSTOR, please contact support@jstor.org.

Wiley, Royal Anthropological Institute of Great Britain and Ireland are collaborating with JSTOR to digitize, preserve and extend access to Man 
ORIGINAL ARTICLES.

\section{Peru. $\quad$ With Plate C.}

Peruvian Tapestries at Toronto. By A. C. Breton.

1914 , contains a number of unique treasures already. There is the sacred hanging or curtain, from Gondar, taken in the Abyssinian Expedition of 1867, and said to be 800 years old. It has a peculiar design, worked over in silk cord with rich and archaic colours. The director, Mr. C. Currelly, while in Egypt, collected a quantity of palæolithic implements in the Libyan desert, and undertook the making of a reproduction of the great relief of the Punt Expedition in the temple at Deir el Bahri, Thebes. Each stone was moulded separately by a special process with wax and tinfoil, and then coloured from the original by Mr. W. Tyndale and another artist. The result is a perfect facsimile, unattainable by an ordinary cast, where the carving has the extreme delicacy of some of these Egyptian reliefs, and was well worth the cost and trouble. As an example of the highest art it will be most valuable to Canada.

Early Chinese bronzes and small painted clay figures from ancient Chinese graves, beautiful Persian pottery, and a fine Eskimo collection, are conspicuous among many interesting things. Two dark green polished stone axes, although found in China, are said to be distinctly of the New Guinea type, both in form and material.

The remarkably fine I c a tapestries illustrated in the Plate were obtained by Dr. J. Tello during his expedition to Southern Peru

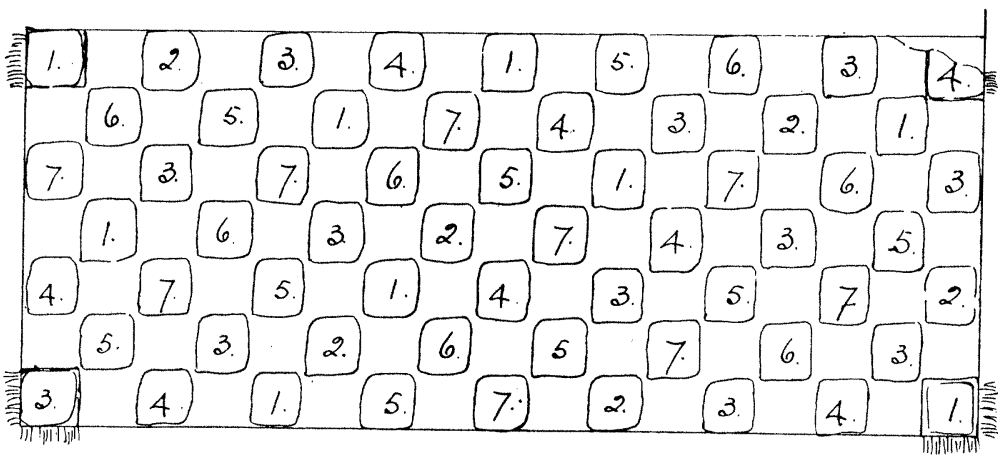

Fig. 3.-DIAGRAM OF COLOUR ARRANGEMENT OF ICA TAPESTRY WITH CONDOR FIGURES.

in 1915. He reported sad destruction of the contents of ancient cemeteries there owing to the impossibility of supervision. To Dr. Max Uhle belongs the credit of the discovery of the Ica and Nazca pre-Inca culture, in a land that has long been desert. The specimens of painted pottery brought by him to the Museum at Lima, and others since acquired by the British Museum and the Museum of Natural History in New York, are unsurpassed in perfection of technique.

These two pieces of tapestry appear to have been a pair, being about the same size. They may have formed the skirts of two priestesses, arranged like those of Mexican women, the piece of stuff folded in pleats at the waist and held together by a long woven band, the ends overlapping in front. The width would be suitable for the length of a skirt, the pleats rising above the waist. 'This supposition seems preferable to the notion that they were shawls.* The one with human figures has a red ground with a black rectangle at each corner. The other has a black ground with red rectangles at the corners.

Mr. Currelly has kindly supplied the following information :-

The four tapestries (two are in Boston, at the Fine Art Museum) were found in a square tomb about twelve feet across and moderately deep. I believe nothing else but the body was in the

* The over-garment was usually a kind of poncho with openings for head and arms. 


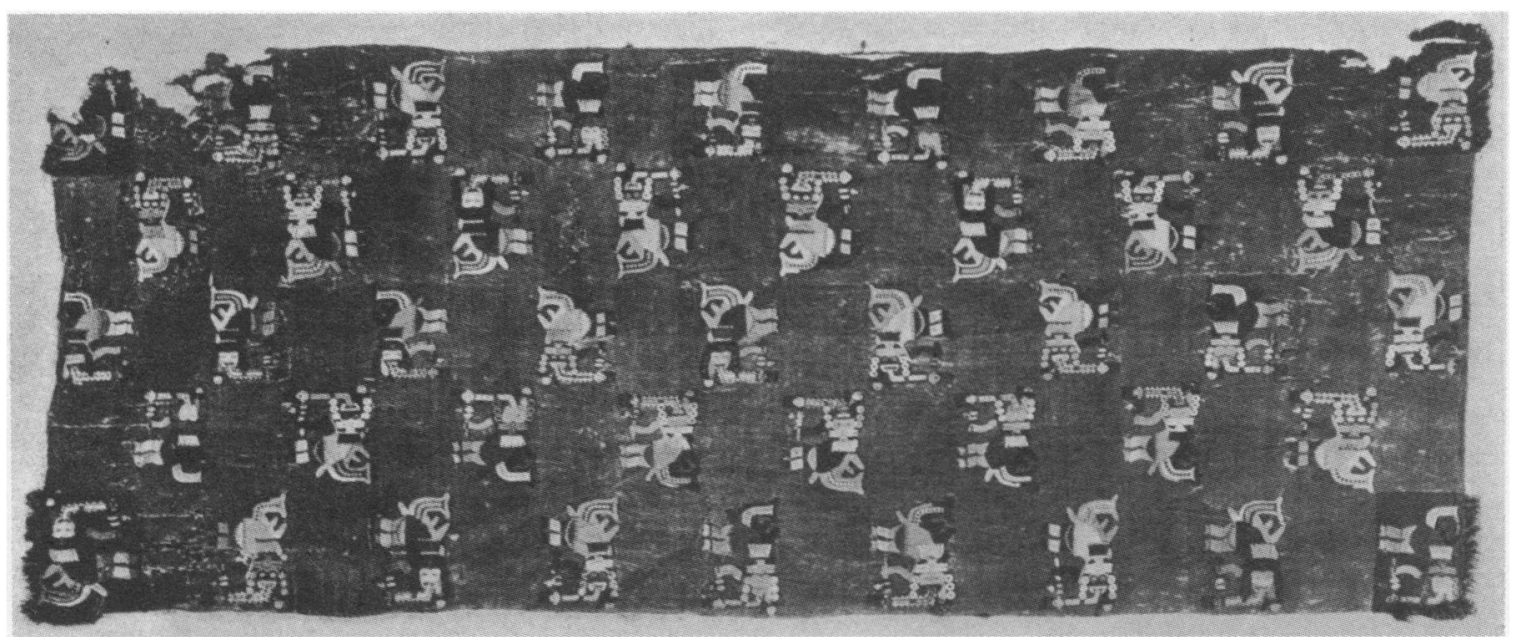

Photo R. Ontario Museum.

Fig. I. PRE-INCA TAPESTRY FROM ICA DESERT, SOUtheRN PERU, SIZE 8' 9" By $3^{\prime} 6^{\prime \prime}$. RED GROUND WITH A RECTANGLE OF BLACK, AND FRINGED AT EACH CORNER.

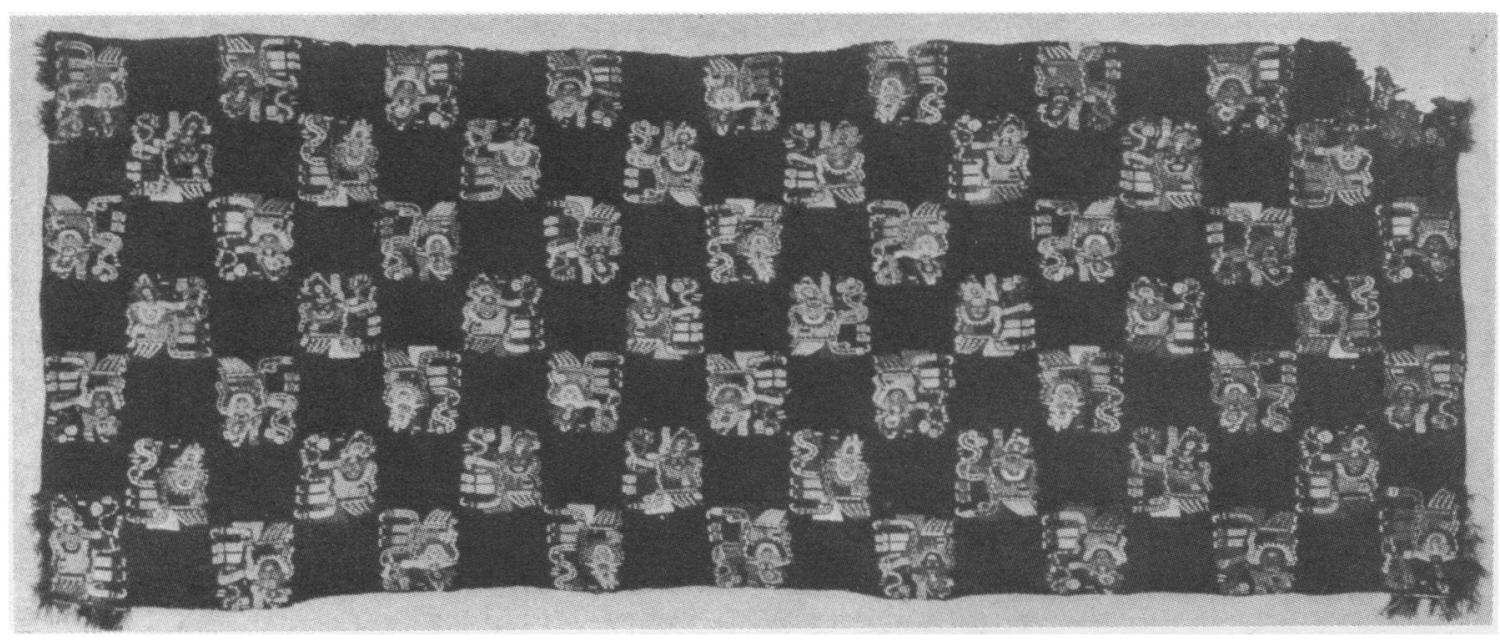

Photo R. Ontario Museum

FIG. 2. PRE-INCA TAPESTRY FROM ICA DESERT, SOUTHERN PERII, SIZE 8' 8" BY 3' 2 ". BLACK GROUND WITH A FRINGED RED RECTANGLE AT EACH CORNER.

PERUVIAN TAPESTRIES AT TORONTO. 
tomb. The tapestries are extraordinarily beautiful in colour. The following colours were used : Two shades of blue, one very pale, the other a kind of periwinkle shade; two shades of yellow, two of brown, olive green, a light pinkish red, crimson red, dark reddish purple, and black. The material would stand very little wear, as the fibre has become short and breaks easily. All the colours were used in different combinations on each figure.

Mr. Currelly has had diagrams made to show the positions of figures in which the main colours are identical. Without any definite sequence, there is an evident intention to have alternate figures alike diagonally, on the piece with the condors, whilst there are also sequences in the horizontal rows. 'This piece has seven combinations of colours, whilst the other has nine, with further minor differences. Except in a few cases, the head-dresses of the human figures are in two colours,

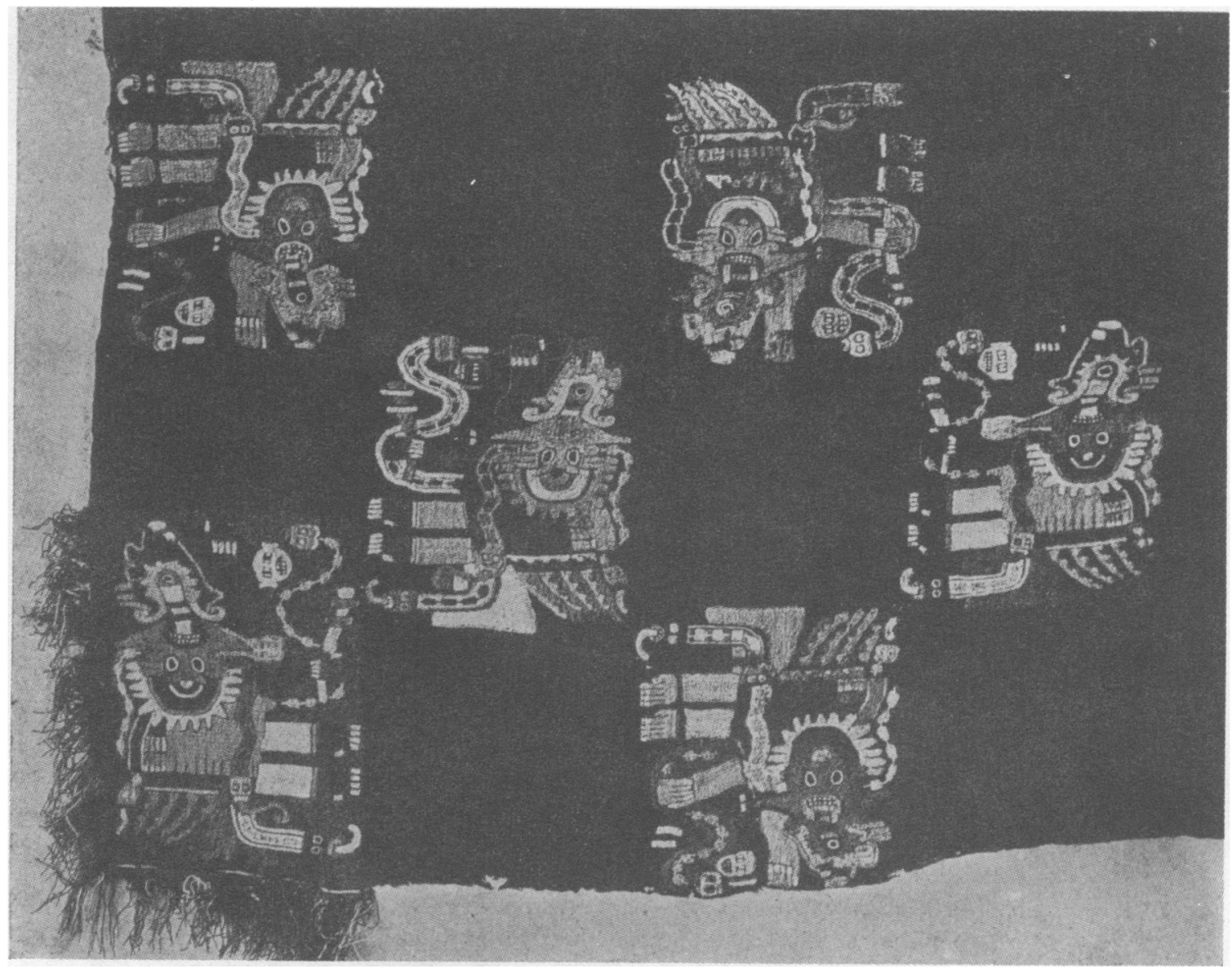

[Photo by Royal Ontario Museum

Fig. 4.-DETAILS OF ICA TAPESTRY WITH CONDOR FIGURES OF FIFTH, SIXTH, AND SEVENTH ROWS.

the upstanding feathers the same as the circular side ornaments, and the centres of the latter the same colour as the cross-pieces (conventionalised winged faces?).

In studying the designs. it will be found that in each case they begin at the top right-hand corner and proceed in boustrophedon fashion, the figures following each other along the rows horizontally, floating downwards until they end with the last figure, turning upwards at the bottom left-hand corner. It is necessary to look at each row so that the heads face downwards, and they must have been worked in that position, turning the material accordingly. In the condor piece the end figures [ 34$]$ 
(left hand) of the first, third, and fifth rows are twisted round towards the next row below. (See Fig. 4.)

The treatment of the sixty crested condor figures is somewhat similar to that of the figures on the Puerta del Sol at Tiahuanaco, but in one hand a human head is held by the hair, in the other is probably a ceremonial dance rattle (Note 1). They have elaborate collars, from which hang the bags of coca as one sees on the mummies, and small snakes twist about them. The forty-three human figures on the other tapestry also hold rattles (usually in the left hand like dancers) and a small head hangs below the other hand. The fish-like fins and tail of these figures could be compared with some in the sculptures and paintings at Chichen Itza, Yucatan, where the feathered serpent changes in convention to fins (Note 2).

The Royal Ontario Museum is at present only one-sixth in size of what is planned. The building cost $£ 70,000$, and the maintenance cost $£ 7,000$ a year, half contributed by the University of Toronto and half by the Provincial Government. It contains five complete museums, each with a director paid by the University; Economic Geology (so important in Canada, where new minerals are being constantly found), Biology, Palæontology, Mineralogy, and Archæology, the last at present the most important. Practically every object in the museum, or the money that obtained it, has been presented, mainly from Toronto, but also with the aid of some extremely generous English friends, often at very high cost. It will become an important factor in the general education of the people of Ontario, the objects being chosen chiefly as examples of art. This is necessary in a recently populated country where the aboriginal culture has been forgotten. The museums at Ottawa and New York are now endeavouring to interest manufacturers and others in the ancient native designs, and to promote their use for various purposes.

A. C. BRETON.

\section{NOTES.}

Note 1.-At Tiahuanaco the condor figures (the middle row) on either side of the central deity look upwards towards him, whilst in the tapestry they are looking down, and are only clear when seen in that position. Many details are not visible in the photographs.

Note 2.-Miss Sarah Flint, of the Boston Fine Arts Mnseum, sent photographs of the Ica tapestries there, bought from Dr. Tello, partly illustrated in the Museum Bulletin of October, 1916. The four principal pieces have the same brilliant colouring and are similar in size and arrangement of design to those of Toronto, especially those numbered 16.31 and 16.33, which correspond closely in style. Though no definite account of provenance was preserved, these are probably the other two of the four from one tomb mentioned by Mr. Currelly. Both have five rows of downward-floating figures (forty-eight in 16.31, fifty-three in 16.33), with alternate blank squares forming a sort of check pattern, and arranged so that three rows have the heads downward, whilst the other two rows must be reversed in order to be seen in that position, as intended. Like those described above, the series appear to begin at the upper right-hand corner and to end at the lower left-hand corner. In 16.31 the figures have in one hand what seems to be a spear-thrower, and the other hand holds a human head by the hair. Those of 16.33 have a feathered wing, a bird's tail, hands instead of feet, and carry a rattle and spearthrower.

A third piece, 16.34, has ten rows of winged human figures, all upstanding, with the same headdresses as Fig. 1, and hold votive heads. The fourth piece has seven rows, with sixty-seven figures of a little man in a poncho holding a long stick and standing npright, the alternate rows (horizontally) being head downwards. Some of the faces (in front view) have the bird design round the eyes like those of the Puerta

[ 35 ] 
del Sol. Allowing for the difference between a much conventionalised sculpture and imaginative feminine needlework, a connection may be traced between the figures of the tapestries and the Puerta del Sol, where the small human figures in the border carry votive heads.

\section{Zululand : Skin-dressing.}

Vaughan-Kirby.

Skin Dressing: A Description of the Process of Converting the Raw Hides of Game or Domestic Cattle into Articles of Native Wearing Apparel. By F. Vaughan-Kirby, Game Conservator, Nongoma, Zululand, January 24, 1914.

The following description, of the Zulu method of skin dressing, by Mr. F. Vaughan-Kirby, was sent me by the Natal Govermment early in 1914, in answer to my request for information on the subject, through the kindness of Mr. J. R. Boosé, C.M.G., the late Secretary of the Royal Colonial Institute. At some of the informal conferences of Northern Museum Curators there had been

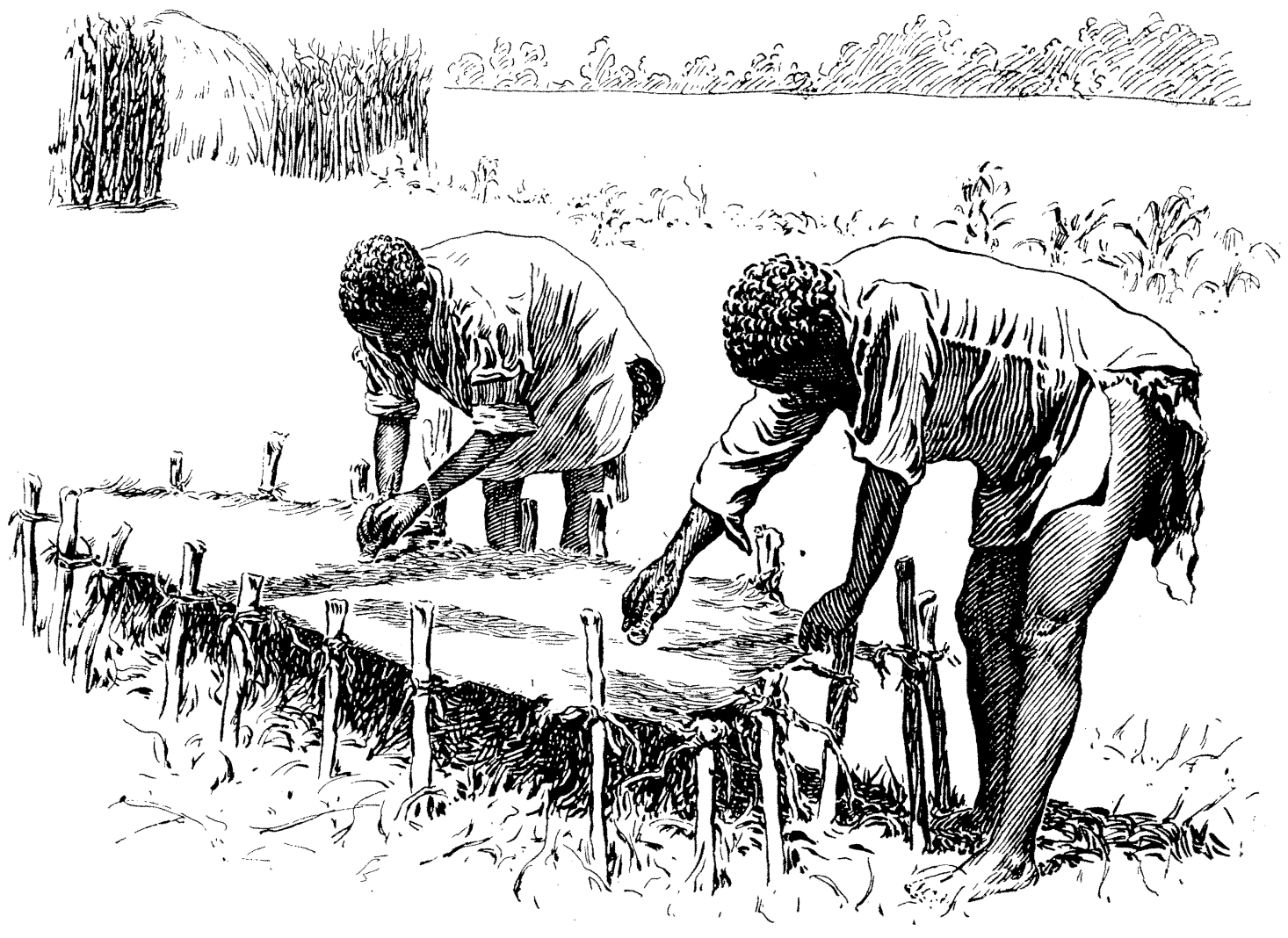

NATIVES USING THE I-ZEMBE.

[From a photograph by F. Vaughan-Kirby.

expressions of opinion on the part of some members that pigmy flints had been used in prehistoric times for the purposes of skin dressing, an opinion which I and others did not hold. As a means of throwing light on the point $I$ tried to get information as to the methods of skin dressing followed by present-day unrisen peoples, and as Livingstone's short account (Missionary Travels, London, 1857, p. 193) gave some clue, I endeavoured to follow it up by obtaining more complete information. Mr. Vaughan-Kirby has very evidently taken great pains in collecting the particulars and noting them down, and as a result we have for the first time a very complete description of Zulu soft leather manufacture. The use of the slain animals' brains as an aid in softening the skin is a point of resemblance with the method used by the North American Indians when engaged on a like job, otherwise, except the stretching of the skin, which it would be difficult to encompass in any other way, the methods adopted by 